\title{
Assessment of the state of the reproductive system of males of Northern sled dog breeds in a kennel
}

\author{
A.S. Barkova ${ }^{1, *}$, I.M. Milshtein ${ }^{1}$, E.I. Shurmanova ${ }^{1}$, and Aleksandr Ustiugov ${ }^{2}$ \\ ${ }^{1}$ Ural state agrarian University, Department of surgery, obstetrics and Microbiology, 620075 \\ Yekaterinburg, Russia \\ ${ }^{2}$ Ural state agrarian University, Department of infectious and Non-communicable Pathology, 620075 \\ Yekaterinburg, Russia
}

\begin{abstract}
Due to the increased interest in sledding in dogs, the assessment of their reproductive function, in particular breeding males, is also relevant at the present time. In the course of the work, the prostate condition was assessed in breeding working animals in a kennel, as well as the quality of sperm in working dogs of different ages, as well as in nonworking groups. The results showed that in $16.8 \%$ of males the prostate is not enlarged, the echostructure is uniform, the contours are even, and the echogenicity is normal. A slight increase in the organ without structural changes is observed in $42 \%$ of the examined animals and the same number of dogs $(42 \%)$, have echostructural changes and increased organ size. Prostate enlargement in most of the examined males of the kennel may be associated with the crowding of their content, as well as the presence of bitches in neighboring enclosures. When assessing semen quality in workers of different age groups and non-group males in various time intervals at different intensity of physical activity. it is noted that the stability of sperm quality identified in males outside of the group, while animals in the system having both long and short-term physical load sperm quality is subject to considerable fluctuations. Thus, under intense load, the sperm quality indicators correspond to the reference values in animals of all groups, while during the long period of rest, working sled dogs have a significant decrease in the quality of sperm, which negatively affects their fertility.
\end{abstract}

\section{Introduction}

Sledding is one of the oldest and most extreme sports with animals. Its history began back in the days when the dog was not only a friend, but also a helper and breadwinner of a person. In the modern world, hundreds of dog sled races are held annually, and Russia is no exception [8].

Sled dogs, and most often they are used in races (Siberian husky, Alaskan husky, Kamchatka sled dog, as well as crossbreeds of sled dogs and hounds), are bred specifically

\footnotetext{
* Corresponding author: barkova.as@mail.ru
} 
to run further, bigger and faster. Sports dogs have a more elongated body, long legs, they are more wiry, while show dogs are calm, proportional and more suitable to the standard of their breed [4].

In Europe and in more than 30 countries of the world, sledding is very developed, and dog racing and dog sledding have also become very popular [1].

Modern sled dogs with distinctive performance are increasingly registered problems in the field of reproduction of offspring [2, 5, 6, 14, 17]. Almost every breeder is interested in preserving and continuing the sports line of their dogs. Most often, males have problems with the prostate gland, in particular prostatitis and prostatic hyperplasia $[3,7,11]$. According to most scientists involved in the classification and analysis of the prevalence of prostate diseases among dogs, the frequency of these diseases directly depends on the age characteristics of animals and their sexual activity. Inthisregard, itisimportanttoassessthequalityofthemale'sspermbeforeplanningbreedinguse $[9,10,12,15]$

At the same time, there are practically no studies of the influence of loads on the state of spermatogenesis in working sled dogs in the available literature. In this regard, an important task is to determine the state of the prostate gland in the studied animals, as well as the effect of different intensity and duration of loads on the quality of sperm of working breeding dogs of different age groups.

\section{Research materials and methods}

Research was conducted in 2020 on the basis of the sled dog kennel "Elbrus", Yekaterinburg. The "Elbrus" nursery has been in existence for 37 years. In 1982, the kennel's dogs participated in the largest polar transcontinental expedition and covered $10,000 \mathrm{~km}$ in 8 months. Over the years, the kennel's dogs have conquered two mountain peaks, for which they were twice listed in the Guinness book of records as the highest mountain teams (climbing Lenin peak (6,400 meters) and Communism peak (7,495 meters) in the Pamirs). Also, the kennel's dogs took part in more than ten major expeditions with geophysicists in the Northern, Middle and southern Urals, participated in dog sled races three times (the last one was Baikal race in 2015, the route is $56 \mathrm{~km}$ ).

To date, the kennel has 55 sled dogs of different sled breeds: Siberian huskies, Samoyeds, Malamutes, Yakut, Chukchi, Taimyr huskies, sled mestizos. All of them work in teams, participate in expeditions and races. One of the main goals of the kennel is and remains to preserve and improve the working qualities of sled dogs. Therefore, the nursery has its own working lines, between which competent crossing is made. And today one of the main problems of the breeder of the Elbrus nursery is the preservation of these lines and prevention of their loss.

To assess the state of the reproductive system of males, 3 groups of animals of different age categories and the degree of participation in work with the team were formed: a young working group -4 males working in teams, aged 2-4 years; a working age group -4 males working in a team, aged 7-9 years; a non-working group -4 males not working in a team, aged 2-4 years.

At the first stage, an ultrasound examination was performed with a linear Sonon $300 \mathrm{~L}$ ultraportable device on the territory of the nursery.

For the study the male was placed on his right side, the hair was removed in the projection of the prostate, and an acoustic gel was applied to ensure that the device was in contact with the skin.

At the next stage a study was conducted to assess the quality of sperm in animals. The ejaculate was taken three times:

1. During the period of intensive loads - in January 2020, when the dogs intensively trained for $25 \mathrm{~km}, 4-5$ times a week; 
2. In the period after exercise - in March 2020, taking sperm immediately after training $10 \mathrm{~km}$;

3. During the dormant period - in April 2020, taking sperm from males untrained for three weeks.

Sperm collection was carried out on the territory of the nursery, indoors. Previously, the male was aroused by a female in the proestrus phase. Sperm was obtained by Masturbation in a clean plastic container. The second and partially third fractions of the obtained ejaculate were collected for the study. Immediately after receiving, the quality of the received ejaculate was evaluated.

The obtained sperm was examined using a LOMO MIKMED-1 microscope(BIOLAM) and a Goryaev counting chamber (model 851).

The newly obtained semen was evaluated according to the following criteria:

1. Macroscopic (visual) assessment of semen: volume of ejaculate, consistency, color, smell.

2. Visual evaluation of semen under a microscope - assessment for density and mobility by the crushed drop method with $2.9 \%$ sodium citrate solution.

3. Evaluation of sperm density by the crushed drop method.

The assessment of sperm activity for motility is conducted using a 10-point system. The study is performed in several fields of view, under a microscope at a magnification of 200 300 times, using the crushed drop method.

5. Determination of the sperm concentration in the semen

Sperm concentration is the degree of sperm saturation. The sperm concentration was determined using a Goryaev counting chamber.

6. Determination of the percentage of live and dead sperm by counting unpainted sperm in a smear with a dye (methylene blue).

7. Calculation of pathological forms of sperm (changes in the shape and size of the head, changes in the tail, cytoplasmic drops, thickening in the body or tail).

\section{Results and discussion}

Ultrasound examination showed that in $16.8 \%$ of males, the prostate is not enlarged, the echostructure is uniform, the contours are even, and the echogenicity is normal. A slight increase in the organ without structural changes is observed in $42 \%$ of the examined animals and the same number of dogs $(42 \%)$, have echostructural changes and increased organ size. The results of ultrasound examination of the prostate are shown in table 1.

Table 1. Summary table of results of ultrasound examination of the prostate

\begin{tabular}{|c|c|c|c|c|c|}
\hline & Nickname & Group & Prostatesize(mm) & Echostructure,echogenicity & Contour \\
\hline 1 & Disa & $\begin{array}{c}\text { Working, } \\
\text { young }\end{array}$ & $37 * 28 * 45$ & Homogeneous, normal & Smooth \\
\hline 2 & Tor & $\begin{array}{c}\text { Working, } \\
\text { young }\end{array}$ & $39 * 33 * 45$ & Homogeneous, normal & Smooth \\
\hline 3 & Sever & $\begin{array}{c}\text { Working, } \\
\text { young }\end{array}$ & $33 * 28 * 32$ & Homogeneous, normal & Smooth \\
\hline 4 & Garrik & $\begin{array}{c}\text { Working, } \\
\text { young }\end{array}$ & $35 * 42 * 35$ & Homogeneous, normal & Smooth \\
\hline 5 & Tima & Working, old & $34 * 40 * 43$ & Non-homogeneous, normal & Smooth \\
\hline 6 & Umka & Working, old & $23 * 25 * 29$ & Homogeneous, normal & Smooth \\
\hline
\end{tabular}




\begin{tabular}{|c|c|c|c|c|c|}
\hline 7 & Patrik & Working, old & $34 * 46 * 30$ & Homogeneous, normal & Smooth \\
\hline 8 & Rey & Working, old & $29,5 * 34 * 43$ & Non-homogeneous, normal & Smooth \\
\hline 9 & Rocky & Non-working & $38 * 38 * 33$ & Homogeneous, normal & Smooth \\
\hline 10 & Dema & Non-working & $25 * 20 * 29$ & Homogeneous, normal & Smooth \\
\hline 11 & Vegas & Non-working & $32 * 27 * 34$ & Homogeneous, normal & Smooth \\
\hline 12 & Bonya & Non-working & $38 * 35 * 42$ & Homogeneous, normal & Smooth \\
\hline
\end{tabular}

Normally, the size of the prostate gland varies greatly depending on the age, breed, and size of the dog. According to P. A. Khorishko (2004), adult males weighing $20-25 \mathrm{~kg}$, the prostate has a length of $2.4-3.5 \mathrm{~cm}$, a width of $1.2-2.5 \mathrm{~cm}$ and a height of $2.4-3.5 \mathrm{~cm}$ [13, 17].

The detected increase in the prostate gland of males can be both a sign of prostatitis and benign prostatic hyperplasia. However, it should be taken into account that the size of the prostate gland in healthy dogs positively correlates with their body weight and age and with environmental factors: overexcitation, stress, heavy physical activity, as well as the presence of a female in heat nearby [3]. In this regard, an analysis of the quality of sperm in the studied dogs was performed.

The study of sperm was performed three times depending on the level of physical activity of the animals.

At the first stage, semen analysis was performed in January 2020 in 8 healthy noncastrated males during intense physical activity: $25 \mathrm{~km}$ with loaded sleds, 3-4 times a week, and 4 non-working males.

The results showed that in all groups there was a moderate volume of ejaculate, with the largest volume of sperm recorded in animals of the young working group $(3.75 \pm 1.7 \mathrm{ml})$, the smallest - in the non-working group $(1.7 \pm 0.5 \mathrm{ml})$;

Table 2. Study of ejaculate during intense exercise

\begin{tabular}{|c|c|c|c|c|}
\hline Indicators & Normal & $\begin{array}{c}\text { Working, } \\
\text { young group }\end{array}$ & $\begin{array}{c}\text { Working, old } \\
\text { group }\end{array}$ & $\begin{array}{c}\text { Non-Working } \\
\text { group }\end{array}$ \\
\hline Volume (ml) & $\begin{array}{c}\text { Second fraction } \\
\approx 0,5-3 \mathrm{ml} \\
\text { Third fraction } \\
\approx 15-20 \mathrm{ml}\end{array}$ & $3,75 \pm 1,7$ & $2,75 \pm 0,87$ & $1,7 \pm 0,5$ \\
\hline Colour & $\begin{array}{c}\text { The second } \\
\text { fraction is white } \\
\text { or cream, the } \\
\text { third fraction is } \\
\text { transparent }\end{array}$ & White & White & White \\
\hline Smell & None & None & None & None \\
\hline Consistency & Semiliquid & Semiliquid & Semiliquid & Semiliquid \\
\hline Density & $\begin{array}{c}\text { Thick, medium } \\
(300-1000 \\
\text { millionin } 1 \\
\text { ejaculate) }\end{array}$ & Medium & Thick & Thick \\
\hline Mobility (\%) & $<70 \%$ & $82,8 \pm 7,5$ & $79,8 \pm 14,55$ & $87,8 \pm 6,8$ \\
\hline $\begin{array}{c}\text { Concentration } \\
\text { (million/ml) }\end{array}$ & $\begin{array}{c}\approx 300-800 \\
\text { million/ml }\end{array}$ & $309,8 \pm 82,9$ & $397 \pm 98,3$ & $511 \pm 66,9$ \\
\hline $\begin{array}{c}\text { Pathologicalfor } \\
\text { ms (\%) }\end{array}$ & $>20 \%$ & $6,3 \pm 4,7$ & $11,3 \pm 6,3$ & $9 \pm 4,1$ \\
\hline $\begin{array}{c}\text { Dead and alive } \\
(\%)\end{array}$ & $>20 \%$ & $19,5 \pm 20,6$ & $10,5 \pm 7,4$ & $9,3 \pm 4,3$ \\
\hline
\end{tabular}


Color, smell, and consistency within the reference range.

When evaluating sperm density, it was found that the most dense sperm is in males of the age and non-working groups, and medium-density sperm is in the young working group, which gives reason to believe that physical activity can directly or indirectly affect fertility.

The highest percentage of sperm motility in the non-working group $(87.8 \pm 6.8 \%)$ and slightly lower than normal in the age group $(79.8 \pm 14.55)$, which, in turn, may be the result of age-related changes.

The highest concentration of sperm in semen was observed in non-working animals $(511 \pm 66.9 \mathrm{million} / \mathrm{ml})$, while in young animals $(309.8 \pm 82.9 \mathrm{million} / \mathrm{ml})$ and in age groups $(397 \pm 98.3 \mathrm{million} / \mathrm{ml})$, the indicators were lower than the reference values.

The percentage of pathological forms in all three groups did not exceed $20 \%$, while in the young group it was about $6.3 \%$, but in this group the highest percentage of dead spermatozoa was recorded, about $19.5 \%$.

Thus, according to the assessment, all groups received good quality ejaculate, which corresponds to the normal fecundity of the studied males, even during intense exercise. The owners of the highest quality sperm in this study are representatives of the non- working group.

At the second stage, the sperm quality was evaluated in males during the post-exercise period. The analysis was carried out in March 2020 in 8 males who ran $10 \mathrm{~km}$ with loaded sleds once before the study, as well as in 4 non-working males.

The largest volume of ejaculate obtained was observed in the age group $(2.63 \pm 1.11 \mathrm{ml})$. Color, smell, and consistency within reference intervals in all three groups of animals. Thick sperm is observed, as in the previous study, in the age and non-working groups. The young group has an average density, which confirms the influence of loads on the quality of the resulting ejaculate.

The percentage of mobility in all subjects is more than $70 \%$, best of all in the nonworking group $(88 \pm 3.56 \%)$. The highest concentration in the age group $(637 \pm 161.4$ million/ml), and the lowest in the non-working group (469.8 $\pm 76 \mathrm{million} / \mathrm{ml})$.

Table 3. Study of ejaculate in the period after exercise

\begin{tabular}{|l|c|c|c|c|}
\hline Indicators & Normal & $\begin{array}{l}\text { Working, } \\
\text { young group }\end{array}$ & $\begin{array}{l}\text { Working, old } \\
\text { group }\end{array}$ & $\begin{array}{l}\text { Non-Working } \\
\text { group }\end{array}$ \\
\hline Volume (ml) & $\begin{array}{c}\text { Secondfraction } \approx 0.5-3 \\
\text { ml } \\
\text { The third fraction is } \\
\approx 15-20 \mathrm{ml}\end{array}$ & $1,63 \pm 0,25$ & $2,63 \pm 1,11$ & $1,25 \pm 0,65$ \\
\hline Colour & $\begin{array}{c}\text { The second fraction is } \\
\text { white or cream, the third } \\
\text { fraction is transparent }\end{array}$ & White & White & White \\
\hline Smell & None & None & None & None \\
\hline Consistency & Semiliquid & Semiliquid & Semiliquid & Semiliquid \\
\hline $\begin{array}{l}\text { Density } \\
\text { Thick, } \\
\text { medium } \\
\text { millionin 1 ejaculate) }\end{array}$ & Medium & Thick & Thick \\
\hline Mobility (\%) & $<70 \%$ & $83,75 \pm 8,31$ & $85 \pm 4,09$ & $88 \pm 3,56$ \\
\hline $\begin{array}{l}\text { Concentration } \\
\text { (million/ml) }\end{array}$ & $\begin{array}{r}\approx 300-800 \\
\text { million/ml }\end{array}$ & $546,8 \pm 357,9$ & $637 \pm 161,4$ & $469,8 \pm 76$ \\
\hline $\begin{array}{l}\text { Pathologicalfo } \\
\text { rms (\%) }\end{array}$ & $>20 \%$ & $19,25 \pm 9,43$ & $18,25 \pm 6,24$ & $18,5 \pm 5,8$ \\
\hline $\begin{array}{l}\text { Dead and alive } \\
(\%)\end{array}$ & $>20 \%$ & $17,75 \pm 11,15$ & $22,25 \pm 18,58$ & $15,25 \pm 8,66$ \\
\hline
\end{tabular}


The percentage of pathological forms in all groups is slightly lower than $20 \%$. And the indicator of dead spermatozoa is higher than normal in the age group by $2.25 \%$ $(22.25 \pm 18.58 \%)$. For young and non - working groups, the indicator is within the reference interval.

According to the study, males of all groups have sperm of high quality and suitable for use in breeding purposes. The quality of the obtained ejaculate is especially noted in working groups in comparison with non-working males. Based on this, we can conclude that short-term physical activity has a positive effect on the high quality of sperm in working groups of males.

At the third stage of research, the quality of sperm during the dormant period of animals was evaluated. The analysis was performed in April 2020 in 12 males during the period of rest and lack of physical activity (table 4).

The results showed that the largest volume of ejaculate was recorded in males of the age group and amounted to $3.5 \pm 0.5 \mathrm{ml}$, the smallest in animals of the non - working group$1.2 \pm 0.5 \mathrm{ml}$. Color, smell, and consistency in all groups, as in previous studies, are within the normal range.

Table 4. Study of the ejaculate at rest

\begin{tabular}{|c|c|c|c|c|}
\hline Indicators & Normal & $\begin{array}{l}\text { Working, young } \\
\text { group }\end{array}$ & $\begin{array}{l}\text { Working, old } \\
\text { group }\end{array}$ & $\begin{array}{l}\text { Non-Working } \\
\text { group }\end{array}$ \\
\hline Volume (ml) & $\begin{array}{l}\text { Secondfraction } \approx 0.5-3 \mathrm{ml} \\
\text { The third fraction is } \approx 15- \\
\qquad 20 \mathrm{ml}\end{array}$ & $3,2 \pm 0,25$ & $3,5 \pm 0,5$ & $1,2 \pm 0,5$ \\
\hline Colour & $\begin{array}{l}\text { The second fraction is } \\
\text { white or cream, the third } \\
\text { fraction is transparent }\end{array}$ & White & White & White \\
\hline Smell & None & None & None & None \\
\hline Consistency & Semiliquid & Semiliquid & Semiliquid & Semiliquid \\
\hline Density & $\begin{array}{l}\text { Thick, medium ( } 300-1000 \\
\text { millionin } 1 \text { ejaculate) }\end{array}$ & Medium & Medium & Thick \\
\hline Mobility (\%) & $<70 \%$ & $54,5 \pm 10,9$ & $53,5 \pm 9,68$ & $87,5 \pm 3,32$ \\
\hline $\begin{array}{l}\text { Concentration } \\
(\text { million } / \mathrm{ml})\end{array}$ & $\approx 300-800$ million $/ \mathrm{ml}$ & $366 \pm 84,9$ & $351 \pm 57,54$ & $483,5 \pm 69,82$ \\
\hline $\begin{array}{l}\text { Pathologicalf } \\
\text { orms }(\%)\end{array}$ & $>20 \%$ & $23,35 \pm 6,7$ & $20,5 \pm 9,19$ & $12,7 \pm 6,47$ \\
\hline $\begin{array}{l}\text { Dead and } \\
\text { alive }(\%)\end{array}$ & $>20 \%$ & $51,5 \pm 13,4$ & $44,5 \pm 34,9$ & $19 \pm 5$ \\
\hline
\end{tabular}

Working groups have an average sperm density, while non-working groups have a thick one. Mobility above $70 \%$ is observed only in the non-working group $(87.5 \pm 3.32 \%)$, in animals of the young working group and the age working group there is a significant decrease in sperm activity $-15.5-16.5 \%$ below the physiological norm $-54.5 \%$ and $53.5 \%$ ), respectively.

The concentration of sperm in the semen of males of all groups was within the reference values, but the best indicator was observed in animals of the non-working group $(483.5 \pm 69.82 \mathrm{million} / \mathrm{ml})$, in the working groups the concentration was in the range of 350 $370 \mathrm{million} / \mathrm{ml}$.

The lowest percentage of pathological forms (12.7\%) and dead spermatozoa (19\%) was observed in the non-working group. In the young working group, the percentage of pathological forms is higher by $3.35 \%$, and the percentage of dead sperm is higher by $31.5 \%$, which indicates a low quality of this ejaculate. Similar indicators were registered in 
animals of the age group, where the percentage of dead spermatozoa is higher by $24.5 \%$, and the percentage of pathological forms is higher by $0.5 \%$.

Thus, according to the results of the study, it can be concluded that the highest quality sperm was detected in the group of non-working males, which indicates their high fertility. In the working groups, the indicators are almost identical and correspond to the low quality of sperm during a long period of absence of physical activity.

\section{Conclusion}

The conducted ultrasound examination showed that almost all male subjects had a moderate increase in the prostate, while maintaining a uniform echo structure and normal echogenicity. The reasons for these results may be factors such as joint walking of males and the presence of breeding bitches on the territory of the nursery.

When evaluating the quality of sperm, it was found that the volume, color, smell and consistency of all groups does not exceed the reference values. In all three studies, the young working group had an average sperm density, low concentration during intense exercise and rest (within $350 \mathrm{million} / \mathrm{ml}$ ), an average percentage of pathological forms and live/dead sperm, and normal mobility of about $80-85 \%$ (except for the rest period $-54.5 \%$ ). The age group has indicators identical to the animals of the young working group. In the non-working group, the highest and most stable indicators of sperm quality were recorded, relative to the animals of the working groups.

At the same time, working sled dogs of both groups have a significant decrease in the quality of sperm during rest and the highest indicators after short-term physical activity.

Thus, based on the conducted research, it can be concluded that in working sled dogs, physical activity on animals has a significant impact on the quality of sperm. In this regard, in working animals used in breeding work, it is necessary to continuously perform shortterm training, in particular in the off-season, as well as to conduct spermogram studies before the planned binding for further successful breeding use.

\section{References}

1. E.V. Alexandrova, L.Sh. Pestryaeva, O.A. Peshkumov, Bulletin of the Chuvash state agricultural Academy, 1(4), 32-35 (2018)

2. S.S. Bogdanova, A.A. Stekolnikov, M.A. Ladanova, Issues of legal regulation in veterinary medicine, 3, 93-95 (2019)

3. A.A. Volkova, A.M. Shabanov, N.A. Kozlov, Bulletin of the Russian Academy of agricultural Sciences, 4, 73-74 (2007)

4. A.V. Dikov, M.V. Sizova, Comparative analysis of exterior and constitutional features of sled dogs of different genotypes, 7, 44-51 (2018)

5. A.V. Dikov, M.V. Sizova, Chief zootechnic, 8, 33-39 (2018)

6. G.P. Dyulger, P.G. Dyulger, E.S. Sedletskaya, N.I. Kolyadina, Russian veterinary journal, 8, 34-38 (2017)

7. G. Ingland, D. Simpson, M. Harvey, Guide to reproduction and neonatology (British Association for veterinary medicine of small animals, M.: Sofion, 2004)

8. K.V. Krasnolobova, A.G. Bychaev, Bulletin of the student Scientific society, 10(1), 136-139 (2019)

9. E.A. Korochkina, K.V. Plemyashov, Hippology and veterinary medicine, 4(10), 111$114(2013)$ 
10. O.V. Perlicka, A.N. Shestakov, D.A. Tsyvunin, M.V. Kasimov, V. Burkova, Veterinary science, 5, 37-40 (2019)

11. O.V. Terletskaya, A N. Shestakova, Veterinarian, 1, 42-46 (2017)

12. V.G. Turkov, I.O. Turubanova, A.N. Martynov, V.V. Cibulin, Agrarian Bulletin of the upper Volga region, 4(25), 36-40 (2018)

13. P.A. Horishko, Bulletin Of Veterinary Medicine, 3, 36-41 (2004)

14. A. Chłopik, A. Wysokińska, Reproduction in Domestic Animals, 55(2), 113-126 (2020)

15. Giovanni Restrepo B., Carlos Andrés Madrid R., Laura Prieto R., Alexandra Usuga S., Juan Esteban Duque C., Revista de InvestigacionesVeterinarias del Peru, 28(4), 876885 (2017)

16. E.C. Feldman, R.W. Nelson, C. Reusch, J.C. Scott-Moncrieff, Canine and Feline Endocrinology, (Imprint: Saunders, 2015)

17. K.T. Kirchhoff, K. Failing, S. Goericke-Pesch, Reproduction in Domestic Animals, 52(6), 945-952 (2017) 